\title{
Preliminary geochronology results from dredging the Rio Grande Rise: NBP1808
}

\author{
PETER DAVIDSON $^{1}$ AND ANTHONY KOPPERS ${ }^{2}$ \\ ${ }^{1}$ College of Earth, Ocean, and Atmospheric Sciences (CEOAS) \\ ${ }^{2}$ Oregon State University \\ Presenting Author: davidspe@oregonstate.edu
}

Expedition NBP1808 on the I/B Nathan B. Palmer completed 32 dredges between October and December, 2018 from locations on the Rio Grande Rise large igneous plateau and several seamounts in the region. Twenty-six samples were chosen for geochronology from 12 dredge locations on the Rio Grande Rise to better understand the geochronological history of this large igneous province formed on the South American plate and to provide clues to its relationship with the Walvis Ridge and Tristan-Gough hotspot(s) on the conjugate African plate. ${ }^{40} \mathrm{Ar} /{ }^{39} \mathrm{Ar}$ results from plagioclase separates are expected by May 2021 and will be used to test the tectonic reconstructions in Sager et al. [1], in particular the presence of micro-plate activity between 92 and $66 \mathrm{Ma}$ that would predict the presence of nonlinear age progressions throughout the East Rio Grande Rise. The broad basin separating the West and East Rio Grande Rise implies at least some amount of extended history of elevated magmatism. High resolution geochronology will help determine whether or not magmatism at Rio Grande Rise was prolonged or punctuated and help to reveal the influence of ridge and plume processes between the Rio Grande Rise and the Valdivia Bank that is part of the older Walvis Ridge. Ages will also allow for ground-truthing of magnetic anomaly reversal picks within the Rio Grande Rise.

[1] Sager W.W., Thoram S., Engfer D.W., Koppers A.A.P., Class C., (in press). Late Cretaceous Ridge Reorganization, Microplate Formation, and the Evolution of the Rio Grande Rise - Walvis Ridge Hot Spot Twins, South Atlantic Ocean. Geochemistry Geophysics Geosystems. 